\title{
Developing EFL Vocabulary through Speaking and Listening Activities
}

\author{
Dr. Lindita Kacani \\ Dr. Juliana Cyfeku \\ Faculty of Education and Philology, University of Korca, Albania \\ Email: Ikacani@yahoo.com/Email: juliana.cyfeku@gmail.com
}

\section{Doi:10.5901/ajis.2015.v4n3s1p390}

\section{Abstract}

Vocabulary is an important aspect of language and communication skills. Teaching new vocabulary words in a foreign language classroom can be a challenge for many teachers. This is because a complete knowledge of a word needs far more than simply recognizing the word or being able to give its meaning; it includes learning its: form (spoken and written form, wordparts), meaning (form and meaning, concepts and referents, associations) and use (grammatical functions, collocations and constraints on use). Since the aim of English language school program is to learn English for communicative purposes, this article, based on current research on foreign language vocabulary teaching and learning, appeals to the use of some very important strategies and techniques for effective vocabulary teaching while building listening and speaking skills: dividing text vocabulary into active and passive ones, effectively organizing and focusing repetition, using the target foreign language in different phases of the lesson and selecting effective teaching and learning activities. These strategies provide good opportunities for learners to extend the knowledge of their actual vocabulary and acquire new words of the target language in a classroom based setting.

Keywords: vocabulary, foreign language, speaking, listening, activity.

\section{Introduction}

Referring to our teaching experience, what is often observed in an EFL classroom is communication marked by low levels of linguistic accuracy and fluency, though learners have studied it for many years. Naturally, the following question arises: what strategies and techniques foreign language teachers need to use for effective vocabulary teaching while building listening and speaking skills and therefore to help their learners learn language for communicative purposes? Through a literature review, the research aims to probe into this issue making proposals for English language teachers for an effective vocabulary teaching and learning referring to foreign language acquisition theory and research.

\section{Important Strategies in Developing EFL Vocabulary through Speaking and Listening Skills}

\subsection{Aspects of word knowledge:}

When dealing with vocabulary it is important to consider what it means to know and learn a word. A complete knowledge of a word needs more than simply recognizing the word or being able to give its meaning, as it usually happens in teaching and learning English as a foreign language in the classroom. Referring to Nation (2005) and Thornbury (2008), knowing and learning a word from the view point of receptive and productive language includes knowing and learning its: form (spoken and written form, word-parts), meaning (form and meaning, concepts and referents, associations) and use (grammatical functions, collocations and constraints on use).

The spoken and written form: The lack of consistency between spelling and pronunciation makes it difficult (or impossible) to base pronunciation on the written form or vice-versa, not only for foreign learners but also for native speakers (Nation, 2005, p. 45). Unfamiliarity with correct pronunciation can result in failing to understand words in spoken English that the learner clearly understands in written English. Moreover, the stress in a word determines the lexical and grammatical meaning of the word ('import--noun, /im'port/-verb.), the length of a phoneme determines the lexical meaning of a word / $/ \mathrm{i}: \mathrm{p} / \mathrm{S} / \mathrm{Sip/}$, and one sound can be represented by one or more letters: IN (cut, come, country, blood, does).

Word-parts: A known stem or affix facilitates the process of word learning and use; it helps the learner to: 
remember its meaning, recognize it in another context, make guesses about the meaning of unknown items and widen the learner's range of expression by using another word instead of the target one, unable to recall it at a certain communicative situation.

Meaning: To understand a word fully, learners must know not only what it refers to, but also when the boundaries are that separate it from words of related meaning (as synonymy, hyponymy, antonymy, part-whole relations) (Gairns \& Redman, 2004, p.13). Moreover, to avoid confusion, learners need to know that a word-form can have: several different meanings not closely related (homonymy: a file - for papers; a tool for cutting) and a referential (denotative) and a connotative meaning.

Grammatical function: In order to use a word correctly, it is necessary to know what part of speech it is and what grammatical patterns it can fit into. This is essential especially in English where: the same word form can be used as a different part of speech (a book / to book a table); the lexical choice, especially of verbs, determines the grammatical construction of the rest of the sentence: Prices rose (intransitive verb); She enjoys music (transitive verb); I left the key at home (complex-transitive verb). What is more, as in other languages, words, in a certain word class, are classified based on their grammatical features (regular/irregular verbs, countable/uncountable nouns, regular/irregular plural noun forms). Unfamiliarity with the irregular forms can result in incorrect learning and use by the learner.

Collocation involves knowing what a word typically occurs with [The earth revolves (not circulates) around the sun]. Such word knowledge helps learners learn and use the target language correctly and fluently. In case of insufficient word collocation knowledge and under the influence of his mother tongue, the learner tends to use grammatically correct but unnatural linguistic sequences ('I took a decision' instead of 'I made a decision').

Constraints on use relates to the sociolinguistic factors (such as the relationship of the speaker to the speaker referred to, their social status, age and gender, the aim of communication, etc.) which lead the language user to choose one word (of a certain style or register) rather than another (from another style or register) in a certain communicative situation. Failure to consider these aspects can result in inappropriate language use.

This multi-dimensional character of the word knowledge needs to be considered in choosing the right strategies and practice activities that enable learners to gradually acquire the targeted aspects of word knowledge and generally speaking English language for communication purpose. The followings are some important strategies and activities that can successfully be used in developing EFL vocabulary through speaking and listening activities. It should be noted that there shouldn't be any complete attention to all the aspects of word knowledge of each word encountered in a material. It is the teacher who selects the words and their aspects needed to be included in learners' active vocabulary based on their importance in the text comprehension, learners' knowledge burden on it and its role in the development of learning skills.

\subsection{Important strategies}

Division of text vocabulary into active and passive ones: The target new words need to be distinguished as active (important to be part of active vocabulary) and passive (needed to be known, but not learned because they will be in focus at a later time when they are more important to the learners). In teaching active vocabulary, it is recommended: to spend time giving examples and asking questions (Doff, 1988, p. 19) so that students can see how the word is used; a rich instruction, exploring several aspects of word knowledge and involving the learners in thoughtfully and actively processing the word (Nation, 2005, p. 95). Good contributions to this strategy are the activities of finding key words in a text and creating a semantic or thinking tree of words or ideas.

Such a strategy - the division of text vocabulary into active and passive ones - should be encouraged to be applied by the learner himself in order to enhance independent vocabulary learning. For this purpose, the teacher should regularly discuss with the students which new words are necessary to be learned for them. Giving reasons for their choices, they are trained in selecting words for their learning.

Repetition is very important for vocabulary learning especially when there is so much to know about each word (as presented above); one meeting with it is not sufficient to gain all the word knowledge and use it fluently. Repetition contributes not only to strength of knowledge but it can enrich previous meetings. By repetition it is not meant a mechanic repetition of the word as a chain of sounds; such a repetition does not help the word memory, but just the word form memory. An effective repetition that strengthens and enriches the word knowledge, involves the exposure of the learner to the word use in different contexts through listening and reading texts and its use in different speaking and writing activities (Nation, 2005).

There has been a great deal of research on how items should be repeated. Referring to Nation (2005), foreign 
language vocabulary research has shown that:

- learning from repetition depends on the spacing of the repetitions and the nature of the repetition;

- spaced repetition (spreading the repetition across a long time period of time) results in more secure learning than massed repetition (spending a continuous period of time, for example $15 \mathrm{~min}$ ).

Pimsleur (1967, cited in Nation, 2005, p. 77), based on research evidence, proposed an exponential scale for the size of space between the repetitions; the general principal that lies behind the spacing is that the older a piece of learning is, the slower the forgetting.

\begin{tabular}{|l|c|c|c|c|c|c|c|c|c|c|c|}
\hline Repetition & 1 & 2 & 3 & 4 & 5 & 6 & 7 & 8 & 9 & 10 & 11 \\
\hline Time spacing before the next repetition & 5 secs & 25 secs & $2 \mathrm{mins}$ & $10 \mathrm{mins}$ & 1 hour & 5 hours & 1 day & 5 days & 25 days & 4 months & 2 years \\
\hline
\end{tabular}

In the same vein, Webb's results of his study (2007) showed greater gains in knowledge for at least one aspect of knowledge each time repetitions increased. Webb suggested that more than ten repetitions may be needed to develop full knowledge of a word.

But there are even research cases, such as that of Webb \& Chang's study (2014) indicating that frequency is just one of many factors that affect learning, finding that the relationships between vocabulary learning and frequency and distribution of occurrence is non-significant.

Concerning the nature of the repetition, experimental evidence has shown that retrieving rather than simply seeing the item again is more effective, as it is more similar to the performance required during normal use (Nation, 2005, p. 79). When there is a delay between the presentation of a word form and its meaning, learners have an opportunity to try to guess or recall the meaning what will result in faster and longer retained learning. Meeting words in listening and reading texts and using them in speaking and writing activities provide opportunity for retrieval. Baddeley (1990, cited in Nation, 2005, p. 79) considered the combination of spaced repetition with retrieval easy to use and widely applicable.

The type of repetition is closely related to the goal of learning: word form, word form - meaning connection, recalling the meaning in different contexts. Nation (2005) noted that more elaborative repetition (extending the meaning of the word and meeting some of its collocations) had stronger effects on passage comprehension measures than repetition of the same information.

Repetition needs to be realized through different activities that enable learners to use the words in different ways aiming to repeat not only the known word aspects, but also to enrich them, extending word meaning and use. Some of the activities suggested to be used are:

\footnotetext{
'Hand computer' aims to organize and focus the word repetition (Nation, 2005, p. 77). It involves the use of a box divided in five sections, where the second section is larger than the first, the third larger than the second and so on. The target words are put into cards and initially go into section 1. When a word is known it is put into section 2. When section 2 fills up, its words are reviewed; those that are still known go into section 3 and those not recalled go back to section 1. The same procedure continuous for the rest sections $(3,4,5)$.

Word cards involve retrieving. In the simplest form of learning from word cards, a learner writes a foreign word on one side of the card and its translation on the other. The learner goes through a set of cards looking at each word and trying to retrieve its meaning. This is criticized and regarded as a decontextualising technique as the word is not in a communicative context, i.e. it is not being used for a communicative purpose (ibid., p. 297). The meaning of the word can be given through translation, a FL definition, a picture, a real object or a sentence. Learners can think new sentences containing the word, imagining contexts of use. Word cards may contain word stems and affixes to help learners focus on word parts.

Word grouping based on certain models: sound-letters, rhymes, stems, affixes, listening to or creating rhymes (Monday wash the clothes / Tuesday - blow your nose/ Wednesday- market day/ Thursday - pay day ...)

Regular tests are also a way to encourage the revision of the vocabulary.
}

Gairns and Redman (2004) proposed FL teachers to use an activity that aims the repetition of the previous lesson(s) before starting the new lesson.

Besides the teacher's responsibility and desire in repeating the target words, the course books and total number of EFL class hours play an important role in this aspect. A good course book provides pupils with materials and contents that give learners opportunities to repeat previously met linguistic items. The number of EFL class hours needs to be considerable as to allow teachers to plan enough review classes for their learners.

Vocabulary learning through clear instructions and definitions. The strategy used for presenting new words, either before listening a text or as they arise in the course of a lesson, is another important factor in vocabulary acquisition. 
Giving the translation of the target word is a traditional and widely used technique in vocabulary presentation as it is the simplest and clearest way of showing the meaning of the word, but it is partial and inadequate because learners cannot see how the word is used and cannot focus on the other aspects of word knowledge.

There are three major factors affecting vocabulary acquisition from oral input:

1. The skill of the teacher related to the way in which a word is defined; good definitions need to be specific, direct, unambiguous and simple; Ellis (1995) and Chaudron (1982) (cited in Nation, 2005, p. 83) suggested that short, direct word definitions work the best in oral input, while too much elaboration of word meaning may cause confusion to learners with limited short-term memories and make it difficult to identify what features are critical to the meaning of the word. Moreover, the use of any unknown words in defining the target word makes comprehension impossible.

2. The skill of the learner. Learners have different learning styles: they learn differently and at different paces because of their biological and psychological differences. Thus, some learners use a holistic model of the word meaning (abandoning a concept if conflicting information occurred); more successful learners use an analytical approach (developing a concept for a word which consisted of several separate meaning components, allowing the incorporation of new information); some students perceive the new linguistic information relying heavily on visual presentation; others prefer spoken language; still others respond better to movement activities (Oxford, 1990). The teacher needs to help the learners to define their styles of perception and facilitate them to memorize new foreign words using the most appropriate techniques for their learning styles.

3. The features of the language involved are important in communicating and comprehending meaning. There are many ways of communicating word meaning: by performing actions, by showing objects, pictures or diagrams, by using translation, by defining in the foreign language, by providing language context clues. Visual techniques, such as real objects, pictures, action performance, are seen as the most advantageous ways of communicating the word meaning as learners see an instance of the meaning and the meaning is stored both linguistically and visually. Moreover, these techniques are often seen as funny by the learners and time-saving for the teacher.

The use of English in different phases and situations of the lesson for practice purposes. Teachers whose own language is not English and who teaches classes of learners who share a common language other than English have many opportunities for using simple English in the course of a lesson. The target foreign language can be used (Doff, 1988):

- in teaching the lesson itself: explaining e new word or grammar point, giving examples, introducing a text, asking questions, etc. It should be noted that the explanations in English should be as simple and clear as possible, so that the learners can understand. When the language needed to be used in explaining is too complex, it is best to use the learners' own language.

- for other activities that are not actually part of the teaching: checking attendance, telling learners where to sit, explaining how an activity works, controlling the class, etc. In such activities, teachers make use of 'organizing' language consisting of simple commands and instructions, which are repeated in each lesson: 'Open/close your books!', 'Come here, please.', 'Be quiet!', 'Who would like to clean the blackboard?', 'Who is absent today?'). If the teacher says them continually in English, learners - even elementary ones- will quickly learn what they mean. Furthermore, the situations that occur in the classroom (a learner arriving late, someone forgetting a book) and chatting in English to the class about topics of interest (things learners have done, feast days and holidays, a school performance, a television program, birthdays, etc.) at the beginning of the lesson (instead of going straight to the textbook) create an opportunity for real language practice and create an English language atmosphere in the classroom, giving the learners the feeling that English is e real language used for communication and not just a school subject.

If the teacher uses English most of the time, it will give learners practice in listening and responding to spoken English, helping them 'pick up' and learn words and expressions beyond the language of the textbook.

Although there are advantages in using English in class, teachers shouldn't feel that they must use it all the time; there are occasions when it can be more useful to use the learners' own language than English. How much the teacher uses English will depend on the level of the class and the teacher's own language ability.

Selecting vocabulary teaching and learning activities. There are numerous practice activities that can be used in learning the target vocabulary while building listening and speaking skills (see Doff, 1988; Gairns \& Redman, 2004, Hedge, 2000; Thornbury, 2008). Selecting the proper ones for a successful teaching and learning, it is essential to consider the following aspects: 
- The goal of the activity. One activity can help learners acquire one or more aspects of word knowledge. After testing learners' knowledge on the target vocabulary, the teacher selects those activities that help learners acquire those aspects that they already lack.

- The psychological conditions the activity uses to help reach the learning goal - noticing, retrieving and generating - which help the learner store the word in the long-term memory. Noticing or attracting the learners' attention to the target words can be affected by several factors, including the salience of the word in the textual input or in the discussion of the text, previous contact that the learners have had with the word, studying a word, guessing it from the context, de-contextualizing it (highlighting it while writing it on the blackboard, negotiating the word meaning with each other or with the teacher). During a receptive (reading/listening) activity, the learner can perceive the form and retrieve its meaning; similarly, wishing to communicate the meaning of the word, the learner retrieves its spoken or written form in a speaking/writing activity. Generating involves meeting or using previously met words in new contexts that differ from the previous meeting with the word. For example: retelling a text from another viewpoint, performing a role-play based on a text. The new meetings force learners to re-conceptualize their knowledge of the word involving a range of variations, from inflection through collocation and grammatical context to reference and meaning.

\section{Conclusion}

Teaching new vocabulary words in a foreign language classroom is a real challenge for teachers since a complete knowledge and competence of a word needs more than simply recognizing it or being able to give its meaning. The following strategies are necessary to be used when aiming at effective vocabulary teaching while building listening and speaking skills and therefore helping their learners learn language for communicative purposes:

Dividing text vocabulary into active and passive ones to save time for more practice activities; repeating the target vocabulary effectively to strengthen and enrich it by considering the spacing of the repetitions and the nature of the repetition; using clear instructions and definitions to enhance vocabulary acquisition from oral input; using English in different phases and situations of the lesson to provide more practice input; selecting vocabulary teaching and learning activities considering the goal of the activity and the psychological conditions it uses to help learners reach their learning goal; increasing the amount of engagement learners have with lexical items in various listening and speaking activities to enhance vocabulary learning.

\section{References}

Doff, Adrian. (1988). Teach English: A training course for teachers. Trainer's handbook. Cambridge University Press.

Gairns, R. \& Redman, S. (2004). Working with words. Cambridge University Press.

Hedge, T. (2000). Teaching and learning in the language classroom. Oxford University Press.

Nation I.S.P. (2005). Learning vocabulary in another language. Cambridge University Press.

Oxford, R. L. (1990). Language learning strategies: what every teacher should know. Heinle \& Heinle Publishers.

Peters, E. (2014). The effects of repetition and time of post-test administration on EFL learners' form recall of single words and collocations. Language Teaching Research, 18(1), 75-94.

Thornbury, S. (2008). How to teach vocabulary. Pearson Longman.

Webb, S. (2007). The Effects of Repetition on Vocabulary Knowledge. Applied Linguistics, 28(1), 46-65.

Webb, S. \& Chang, A. C-S. (2014, November 28). Second language vocabulary learning through extensive reading with audio support:

How do frequency and distribution of occurrence affect learning? Language Teaching Research. Retrieved from http://tr.sagepub.com/ content/early/2014/11/27/1362168814559800.abstract. 